\title{
Kinetics And Mechanism Of The Reduction Of Dichromate Ion By 2-Methyl Pentane-2,4-Diol In Aqueous Hydrochloric Acidic Medium
}

\author{
S. O. Idris*, J. F. Iyun and E. B. Agbaji \\ Department of Chemistry, Ahmadu Bello University, Zaria, Nigeria.
}

\begin{abstract}
The stoichiometry and kinetics of the reduction of dichromate ion by 2-methylpentane-2,4-diol have been investigated in aqueous hydrochloric acid medium at $27 \pm 1^{\circ} \mathrm{C}$. The reaction is first order with respect to oxidant and reductant concentrations and also acid dependent. The empirical rate law conforms to the rate equation:
\end{abstract}

$$
\frac{1}{2} \frac{d\left[\mathrm{Cr}^{3+}\right]}{d t}=a\left[H^{+}\right][\text {pen tan ediol }][\mathrm{Cr}(\mathrm{VI})]
$$

The result of spectroscopic investigation and kinetic studies did not indicate intermediate complex formation. An outer sphere pathway is proposed for this reaction.

\section{INTRODUCTION}

Oxidative properties of $\mathrm{Cr}(\mathrm{VI})$ are of considerable importance in both analysis and oxidation of organic and inorganic substrates ${ }^{1,2,3}$. $\mathrm{Cr}$ (VI) in water exists as $\mathrm{CrO}_{4}^{2-}, \mathrm{HCr}_{2} \mathrm{O}_{7}{ }^{2-}$ and $\mathrm{H}_{2} \mathrm{Cr}_{2} \mathrm{O}_{7}$ ${ }^{2,4}$. Of all these species, $\mathrm{HCrO}_{4}^{-}$has been identified as the only active oxidizing species in aqueous acidic solution 1,2,5,6,7. Although some kinetic information has been published on the oxidation of secondary alcohol by $\mathrm{Cr}(\mathrm{VI}) \quad 1,2, \quad 8-16$ complementary studies on its possible reaction pathways are scanty. It is in the light of this that the present work was undertaken with the aim of providing relevant information on the plausible mechanism for the electron transfer reaction of 2-methylpentane-2,4-diol .

\section{EXPERIMENTAL \\ Materials}

2-methylpentane-2,4-diol (BDH) hereafter referred to as diol was used as supplied in making its standard solution. Sodium dichromate solution in distilled water was then standardized using titrimetric method $^{17}$. A stock solution of $\mathrm{HCl}$ was prepared by diluting the commercial acid (M\&B) and the solution was standardized titrimetrically using sodium carbonate. Stock solutions of sodium methanoate, sodium chloride and sodium ethanoate were prepared from Analar grade salts.

\section{Stoichiometry}

The stoichiometry of the reaction was determined by spectrophotometric titration using the mole ratio method. The concentration of $\mathrm{Cr}_{2} \mathrm{O}_{7}{ }^{2-}$ was kept constant at $0.007 \mathrm{~mol} \mathrm{dm}^{-3}$ while that of diol was varied between 0.001 and 0.036 $\mathrm{mol} \mathrm{dm}{ }^{-3}$ at $\left[\mathrm{H}^{+}\right]=0.6 \mathrm{~mol} \mathrm{dm} \mathrm{dm}^{-3}$ and constant ionic strength $(\mathrm{NaCl})$. The reactions were allowed to stand until the repeated absorbances of the solutions at $\lambda_{\max }=580 \mathrm{~nm}$ were constant. The stoichiometry was then determined from the plot of the absorbance versus [diol].

\section{Kinetic studies}

The rate of the reaction was monitored on a Corning Colorimeter 253 
by observing the rate of increase of absorbance of the product at $580 \mathrm{~nm}$. All kinetic measurements were conducted under pseudo-first order conditions with the diol concentration in at least 30 -fold excess over the $\left[\mathrm{Na}_{2} \mathrm{Cr}_{2} \mathrm{O}_{7}\right]$ at $27 \pm 1^{\circ} \mathrm{C}$.

\section{Acid dependence studies}

The effect of acid on the rate of the reaction was determined by keeping all other conditions constant while varying the acid concentration in the range of 0.4 $\leq \mathrm{H}^{+} \leq 0.8 \mathrm{~mol} \mathrm{dm}^{-3}$.

\section{Effect of ionic strength}

The influence of ionic strength on the rate of the reaction was studied over the range $0.6-1.2 \mathrm{~mol} \mathrm{dm}^{-3}$ using $\mathrm{NaCl}$ as the inert electrolyte while keeping other conditions constant.

\section{Influence of added anions}

The effects of added methanoate and ethanoate ions on the rate of reaction were investigated by varying the concentration of these anions while keeping $\mathrm{r}_{2} \mathrm{O}_{7}^{2-}$, [diol] and ionic strength constant.

\section{RESULTS AND DISCUSSION}

\section{Stoichiometry and product analysis}

The stoichiometry of the reaction between diol and dichromate ion was found to be 1:3. A similar stoichiometry was reported for the reaction between the oxidant and isopropyl alcohol $^{2}$ or pinacol $^{12,18}$.

The colour of the product with $\lambda_{\max }=580 \mathrm{~nm}$ is blue-green which indicates the presence of $\mathrm{Cr}^{3+}$ in the mixture. The ether extract of the product obtained by reacting stoichiometric amounts of reactants at $\left[\mathrm{H}^{+}\right]=0.6 \mathrm{~mol} \mathrm{dm}-$ 3 was subjected to conventional functional group tests ${ }^{19}$, infrared spectroscopy and thin layer chromatographic analyses.

The product extract gave a precipitate with 2,4dinitrophenylhydrazine, negative result for Fehling's test and positive result with Tollen's reagent suggesting that the product contained ketonic functional group. The broad spectrum at 3447.76 $\mathrm{cm}-1$ was assigned to $-\mathrm{OH}$. The peaks at $2858-2977.05 \mathrm{~cm}^{-1}$ indicated symmetrical and antisymmetrical stretching of $\mathrm{CH}_{2}$ and symmetric stretching of $\mathrm{CH}_{3} . \mathrm{C}=\mathrm{O}$ stretch due to ketonic functional group occurred at $1731.22 \mathrm{~cm}^{-1}$. These peaks are in agreement with values reported in the literature for ketone and hydroxyl functional groups ${ }^{20}$.

The ether extract of the product and 2-methylpentane-2,4-diol solution were analysed by comparative thin layer chromatography (tlc). Each of these was spotted on already prepared plate using petroleum ether:ethyl acetate $(3: 2)$ and butanol; acetic acid and water $(4: 1: 5)$ as mobile phases. The spots were located by irradiation of the plate with ultraviolet light. 2-methylpentane-2,4-diol was not moved at all from the base line, but the product moved as a single spot. This suggests the absence of 2-methylpentane2,4-diol in the product. On the basis of these results, 4-hydroxy-4-methyl pentane-2-one is proposed as the name of the organic product of this reaction and the stoichiometry is given as:

$$
\begin{aligned}
& \mathrm{Cr}_{2} \mathrm{O}_{7}{ }^{2}+3 \mathrm{CH}_{3} \mathrm{C}(\mathrm{OH})\left(\mathrm{CH}_{3}\right) \mathrm{CH}_{2} \mathrm{CH}(\mathrm{OH}) \mathrm{CH}_{3}+8 \mathrm{H}^{+} \\
& \rightarrow 2 \mathrm{Cr}^{3+}+3 \mathrm{CH}_{3} \mathrm{C}(\mathrm{OH})\left(\mathrm{CH}_{3}\right) \mathrm{CH}_{2} \mathrm{COCH}_{3}+7 \mathrm{H}_{2} \mathrm{O}
\end{aligned}
$$




\section{Rate law}

Pseudo-first order rate constants $\left(\mathrm{k}_{1}\right)$ obtained from plots of $\log \left(\mathrm{A}_{\infty}-\mathrm{A}_{t}\right)$ versus time (where $A_{t}$ and $A_{\infty}$ are the absorbances at time, $t$ and the end of reaction respectively) showed a linear dependence on diol concentration at constant $\left[\mathrm{H}^{+}\right]$. The first order in [diol] was confirmed by plotting $\mathrm{k}_{1}$ versus [diol], which was linear and passed through the origin. The second order rate constants $\left(\mathrm{k}_{2}\right)$ were obtained from $\mathrm{k}_{1}$ as $\mathrm{k}_{1} /[\mathrm{diol}] . \quad$ The calculated values of $\mathrm{k}_{2}$ in each case were fairly constant (Table 1). Thus the rate of the reaction is:

$\frac{1}{2} \frac{d\left[\mathrm{Cr}^{3+}\right]}{d t}=k_{2}[$ pen tan ediol $][\mathrm{Cr}(\mathrm{VI})]$

$\mathrm{k}_{2}=1.71 \pm 0.04 \times 10^{-3} \mathrm{dm}^{3} \mathrm{~mol}^{-1} \mathrm{~s}^{-1}$

\section{Acid dependence}

A plot of $\mathrm{k}_{2}$ versus $\left[\mathrm{H}^{+}\right]$was linear without intercept indicating that $\mathrm{k}_{2}$ varies with $\left[\mathrm{H}^{+}\right]$according to equation (3).

$$
\begin{aligned}
& \mathrm{k}_{2}=\mathrm{a}\left[\mathrm{H}^{+}\right] \ldots \ldots \ldots \ldots(3) \\
& \quad \mathrm{a}=3.40 \times 10^{-3} \mathrm{dm}^{6} \mathrm{~mol}^{-2} \mathrm{~s}^{-1}
\end{aligned}
$$

When the expression for $k_{2}$ in the equation (3) is substituted into equation (2), the rate equation for the reaction becomes:

$$
\frac{1}{2} \frac{d\left[\mathrm{Cr}^{3+}\right]}{d t}=a\left[\mathrm{H}^{+}\right][\text {pen tan ediol }][\mathrm{Cr}(\mathrm{VI})]
$$

\section{Anion dependence}

The results as presented in Table 2 show that methanoate and ethanoate anions retarded the reaction rate. Chloride ion has been reported to inhibit the chromic acid oxidation of isopropyl alcohol in acetic acid aqueous medium ${ }^{21}$

\section{Ionic strength dependence}

The result as presented in Table 1 shows that the rate decreases with increase in ionic strength suggesting a negative Bronsted - Debye salt effect. This is synonymous with a reaction occurring between oppositely charged species ${ }^{22-24}$. The plot of $\log \mathrm{k}_{2}$ versus square root of ionic strength was linear with a slope of -0.52 , an indication that some other interactions might have taken place to account for the non-integral value of the slope.

\section{Reaction mechanism}

The rate of reductions of many oxyanions usually indicates strong dependence on [acid] 1,2,9,11,12,14,25-29. The $\left[\mathrm{H}^{+}\right]$dependence on the rate may not be unconnected with the various equilibria established in an aqueous solution of chromic acid. The $\mathrm{H}^{+}$consumption must be as a result of conversion of oxoanions to a hydrated cation, $\mathrm{Cr}\left(\mathrm{H}_{2} \mathrm{O}\right)_{6}{ }^{3+}$. Therefore, it is not surprising that rates of the reaction increased with increase in $\left[\mathrm{H}^{+}\right]$. The first order in diol concentration observed in our studies is similar to that observed in chromic acid oxidation of isopropyl alcohol ${ }^{2}$ and oxidation of leucomalachite green by $\mathrm{Cr}(\mathrm{VI})^{7}$.

On the basis of the evidence so far adduced, the following scheme is hereby proposed for the title reaction. 


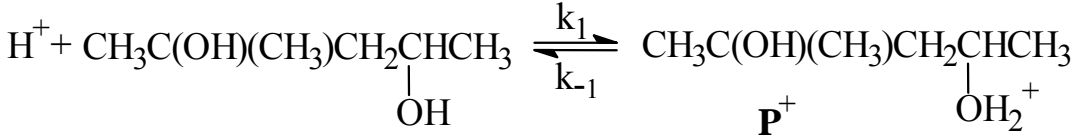

$$
\begin{aligned}
& \mathrm{Cr}_{2} \mathrm{O}_{7}^{2-}+\mathrm{H}_{2} \mathrm{O} \underset{\mathrm{k}_{-2}}{\stackrel{\mathrm{k}_{2}}{\rightleftharpoons}} 2 \mathrm{HCrO}_{4}^{-} \\
& \underset{\mathbf{P}^{+}}{\mathrm{CH}_{3} \mathrm{C}(\mathrm{OH})\left(\mathrm{CH}_{3}\right) \mathrm{CH}_{2} \mathrm{CHCH}_{3}}+\underset{\mathrm{OH}_{2}^{+}}{\mathrm{HCrO}_{4}^{-}} \stackrel{\mathrm{k}_{3}}{\longrightarrow} \underset{\mathrm{CH}_{3} \mathrm{C}(\mathrm{OH})\left(\mathrm{CH}_{3}\right) \mathrm{CH}_{2} \underset{\|}{\mathrm{C}} \mathrm{HCH}_{3}}{\mathrm{CHCH}_{2}}+\mathrm{H}_{2} \mathrm{CrO}_{3}+\mathrm{H}_{2} \mathrm{O}
\end{aligned}
$$

$$
\begin{aligned}
& \underset{\text { OH }}{\mathrm{CH}_{3} \mathrm{C}(\mathrm{OH})\left(\mathrm{CH}_{3}\right) \mathrm{CH}_{2} \mathrm{CHCH}_{3}}+\mathrm{H}_{2} \mathrm{CrO}_{3}+2 \mathrm{H}^{+} \stackrel{\mathrm{k}_{4}}{\longrightarrow} \underset{\mathrm{O}}{\mathrm{CH}_{3} \mathrm{C}(\mathrm{OH})\left(\mathrm{CH}_{3}\right) \mathrm{CH}_{2} \mathrm{CHCH}_{3}}+\underset{\mathrm{Cr}^{2+}}{\mathrm{CH}_{3}}+\underset{\mathrm{H}}{2} \mathrm{O} \\
& \mathrm{Cr}^{2+}+\mathrm{HCrO}_{4}^{-}+2 \mathrm{H}^{+} \stackrel{\mathrm{k}_{5}}{\longrightarrow} \mathrm{Cr}^{3+}+\mathrm{H}_{3} \mathrm{CrO}_{4} \\
& \mathrm{H}_{3} \mathrm{CrO}_{4}+\mathrm{CH}_{3} \mathrm{C}(\mathrm{OH})\left(\mathrm{CH}_{3}\right) \mathrm{CH}_{2} \mathrm{CHCH}_{3}+3 \mathrm{H}^{+} \stackrel{\mathrm{k}_{6}}{\longrightarrow} \underset{\mathrm{O}}{\mathrm{CH}_{3} \mathrm{C}(\mathrm{OH})\left(\mathrm{CH}_{3}\right) \mathrm{CH}_{2} \mathrm{CHCH}_{3}}+\mathrm{Cr}^{3+}+\underset{\mathrm{O}}{4 \mathrm{H}_{2} \mathrm{O}}
\end{aligned}
$$

Rate $=\mathrm{k}_{3}\left[\mathrm{P}^{+}\right]\left[\mathrm{HCrO}_{4}{ }^{-}\right]$

$\left[\mathrm{P}^{+}\right]=\mathrm{K}_{1}[\mathrm{P}]\left[\mathrm{H}^{+}\right]$

$\therefore$ Rate $=\mathrm{K}_{1} \mathrm{k}_{3}[\mathrm{P}]\left[\mathrm{H}^{+}\right]\left[\mathrm{HCrO}_{4}^{-}\right]$

where $\mathrm{P}=$ pentanediol and $\mathrm{P}^{+}=$protonated pentanediol

This is similar to equation (4) where $a=k_{1} k_{3}$

Thus, the proposed mechanism is consistent with the results obtained and this has been rationalised on the basis of the following points:

(i) Inhibition of the rate of reaction by the presence of methanoate and ethanoate ions tends to suggest that the reaction occurs through outersphere pathway. Such rationalisation for anion effect on reaction rate has been made for different systems ${ }^{25,26,29,30}$.

(ii) The absence of gel formation after the addition of methanol and a solution of acrylamide to a partially oxidised mixture shows the absence of a free radical intermediate in the reaction or that the equilibrium constants for the formation of such radical can be assumed to be very small.
(iii)The results of the spectrophotometric measurement displayed no change in $\lambda_{\max }$ from $580 \mathrm{~nm}$ when the absorbance of the reaction mixture was monitored one minute after mixing at different wavelengths. Similar observation has been reported to be in support of outersphere pathway.

(iv) A Lineweaver - Burk modification of Michaelis Menten ${ }^{24,31,32}$ plot of $1 / \mathrm{k}_{1}$ versus $1 /[$ diol] was linear without intercept. This also indicates that intermediate with appreciable equilibrium constants are very unlikely in this reaction.

Convincing arguments that the oxidation of alcohol proceeds through formation of esters of chromic acid have been advanced ${ }^{2,21}$. The co-ordination of reductants to the chromium centre in a step preceding the redox process has been 
observed in a number of reactions of this oxidant $^{11}$ but from (i)-(iv) above, it can be concluded that the spectroscopic and kinetic evidences are not in support of the innersphere mechanism. Therefore we propose outersphere mechanism for this reaction.

Table 1: Rate Constants for the oxidation of 2-methylpentane-2,4-diol by $\mathrm{Na}_{2} \mathrm{Cr}_{2} \mathrm{O}_{7}$ in aqueous $\mathrm{HCl}$ at $\left[\mathrm{Cr}_{2} \mathrm{O}_{7}{ }^{2-}\right]=0.01 \mathrm{~mol} \mathrm{dm}^{-3}, \lambda_{\max }=580 \mathrm{~nm}$ and $\mathrm{T}=27$ $\pm 1^{\circ} \mathrm{C}$

\begin{tabular}{|c|c|c|c|}
\hline$[\mathrm{diol}], \mathrm{mol} \mathrm{dm}^{-3}$ & {$\left[\mathrm{H}^{+}\right] \mathrm{mol} \mathrm{dm}^{-3}$} & $\mathrm{I}, \mathrm{mol} \mathrm{dm}$ & $10^{3} \mathrm{k}_{2}, \mathrm{dm}^{3} \mathrm{~mol}^{-1} \mathrm{~s}^{-1}$ \\
\hline 0.575 & 0.5 & 1.0 & 1.68 \\
0.625 & 0.5 & 1.0 & 1.78 \\
0.700 & 0.5 & 1.0 & 1.68 \\
0.800 & 0.5 & 1.0 & 1.72 \\
0.900 & 0.5 & 1.0 & 1.71 \\
0.625 & 0.4 & 1.0 & 1.32 \\
0.625 & 0.6 & 1.0 & 2.05 \\
0.625 & 0.7 & 1.0 & 2.16 \\
0.625 & 0.8 & 1.0 & 2.69 \\
0.625 & 0.5 & 0.60 & 2.13 \\
0.625 & 0.5 & 0.70 & 2.05 \\
0.625 & 0.5 & 0.90 & 1.89 \\
0.625 & 0.5 & 1.10 & 1.59 \\
0.625 & 0.5 & 1.20 & 1.51 \\
\hline
\end{tabular}

Table 2: Dependence of Second order rate Constant on the added anions for oxidation of 2-methylpentane-2,4-diol by $\mathrm{Cr}_{2} \mathrm{O}_{7}{ }^{2-}$ at $\left[\mathrm{Cr}_{2} \mathrm{O}_{7}{ }^{2-}\right]=0.01 \mathrm{~mol} \mathrm{dm}^{-3}, \lambda_{\max }=580 \mathrm{~nm}$ and $\mathrm{T}=27 \pm 1^{\circ} \mathrm{C}$

\begin{tabular}{|c|c|c|c|c|c|}
\hline $\begin{array}{c}{[\mathrm{diol}]} \\
\mathrm{mol} \mathrm{dm}^{-3}\end{array}$ & $\begin{array}{c}{\left[\mathrm{H}^{+}\right]} \\
\mathrm{mol} \mathrm{dm}^{-3}\end{array}$ & $\begin{array}{c}\mathrm{I}, \\
\mathrm{mol} \mathrm{dm}^{-3}\end{array}$ & $\begin{array}{c}{\left[\mathrm{HCOO}^{-}\right],} \\
\mathrm{mol} \mathrm{dm}^{-3}\end{array}$ & $\begin{array}{c}{\left[\mathrm{CH}_{3} \mathrm{COO}^{-}\right],} \\
\mathrm{mol} \mathrm{dm}^{-3}\end{array}$ & $\begin{array}{c}10^{3} \mathrm{k}_{2}, \\
\mathrm{dm}^{3} \mathrm{~mol}^{-1} \mathrm{~s}^{-1}\end{array}$ \\
\hline 0.625 & 0.5 & 1.0 & 0.05 & - & 1.58 \\
0.625 & 0.5 & 1.0 & 0.10 & - & 1.45 \\
0.625 & 0.5 & 1.0 & 0.20 & - & 1.05 \\
0.625 & 0.5 & 1.0 & 0.25 & - & 0.86 \\
0.625 & 0.5 & 1.0 & - & 0.05 & 1.49 \\
0.625 & 0.5 & 1.0 & - & 0.10 & 1.28 \\
0.625 & 0.5 & 1.0 & - & 0.20 & 0.96 \\
0.625 & 0.5 & 1.0 & - & 0.35 & 0.47 \\
0.625 & 0.5 & 1.0 & - & 0.45 & 0.10 \\
0.625 & 0.5 & 1.0 & - & - & 1.10 \\
0.625 & 0.5 & 1.0 & - & - & 1.20 \\
0.625 & 0.5 & 1.0 & - & - & 1.25 \\
0.625 & 0.5 & 1.0 & - & - & 1.31 \\
0.625 & 0.5 & 1.0 & - & - & 1.32 \\
0.625 & 0.5 & 1.0 & - & - & \\
\hline
\end{tabular}




\section{REFERENCES}

1. Espenson, J. H., Accounts Chem. Res. 3 (1970) 347.

2. Westheimer, F. H., Chem. Rev.45 (1949) 419.

3. Lee, J. D., A new Concise Inorganic Chemistry. $3^{\text {rd }}$ ed. Van Nostrand Reinhold Co Ltd., U.K. 1983.

4. Tony, T. Y and King, E. L ., J. Am.Chem. Soc. 75 (1953) 6180.

5. Schwarzenbach, G. and Meier, J., J. Inorg. Nucl. Chem.8 (1958) 302.

6. Hepler, L .G., J. Am. Chem. Soc.80 (1958) 6181.

7. Ukoha, P. O, Agunwa,U. B. and Okonkwo, E. M., J. Chem. Soc. Nigeria. 26:1 (2001) 81.

8. Westheimer,F. H., J. Am. Chem. Soc.74 (1952) 4387.

9. Kuivila, H.G and Becker,W. J. J., J. Am. Chem. Soc.74 (1963) 5329.

10. Wiberg,K. B and Schafer, H., J. Am.Chem. Soc. 89 (1967) 455.

11. Olatunji, M. A., Ph D. Thesis, University of Glassgow, Glassgow. 1975.

12. Chang, Y .W and Westheimer, F. H., J. Am.Chem. Soc. 82 (1960) 14.

13. Haight, G. P, Jursich,G. M., Kelso, M. T. and Merrill, P., J. Inorg. Chem.24 (1985) 2740.

14. Chatterji, A. C. and Mukherjee, S. K., J. Am.Chem. Soc.80 (1958) 3600.
15. Kemp,T. J. and Walters, W. A., Proc. Roy. Soc. London.A274 (1963) 480.

16. Rocek, J and Riehl, A., Tet. Lett. (1966)1437.

17. Vogel, I. A., A Textbook of Quantitative Inorganic Analysis. E.L.B.S and Longman U.K. 1971.

18. Chatterji, A. C. and Mukherjee, S. K. Z. Physik Chem., 208 (1958) 281.

19. Clarke, H. T., A handbook of Organic Analysis Qualitative and Quantitative, $5^{\text {th }}$ ed., Edward Arnold Publishers Ltd., London, 1975.

20. Price, W. J., The Principle and Practice of Infrared Spectroscopy. $3^{\text {rd }}$ ed. Pye Unicam Ltd, England. 1973.

21. Westheimer, F and Novick, A., J. Chem. Phys. 11 (1943) 506.

22. Atkins, P. W. Physical Chemistry , E.L.B.S, U.K. 1979.

23. Ayoko, G. A, Iyun, J. F and Okechukwu, R.C., Bull. Chem. Soc. Ethiopia.4:1 (1990) 33.

24. Onu, A.D. and Iyun, J.F., J. Chem. Soc. Nigeria. 26 :2 (2001)156.

25. Ukoha, P. O and Iyun, J. F., Nig. J. Chem. Res.4 (1999) 9.

26. Iyun, J. F., J. Chem. Soc. Nigeria. 15 (1990) 80.

27. Lohdip,Y. N., Davies, A. K. and Iyun, J. F., N. J.T.E,15:2 (1998) 57.

28. Lohdip,Y. N., M. Sc. Thesis. Ahmadu Bello University, 1989. 
29. Lohdip,Y. N., Ph. D. Thesis, Ahmadu Bello University, 1999.

30. Lohdip, Y. N. and Iyun, J. F., J. Chem. Soc. Nigeria 18 (1993) 61.

31. Iyun, J. F, Ayoko, G. A. and Lawal, M .H., Indian J. Chem.31A (1992) 943.

32. Michaelis,L. and Menten, M.L., Biochem. Z. 49 (1939) 33.
accepted 18/5/05
received 16/2/05 